\title{
The effect and pharmacology of Yizhi Sheng Hui decoction on Alzheimer's disease
}

\author{
Qiubing $\mathrm{Li}^{1}$, Yi Hou ${ }^{2}$, Baosheng Zhao ${ }^{3}$, Yingfan $\mathrm{Li}^{4}$, Xinyu Zhang ${ }^{1}$, Rong Mei ${ }^{5}$, Shuo Wang ${ }^{1}$, Peng Wang ${ }^{1}$, \\ Ying Liu ${ }^{1}$
}

${ }^{1}$ The Fourth Department of Healthcare, China-Japan Friendship Hospital, Beijing, China; ${ }^{2}$ College of Life Science and Technology, Beijing University of Chemical Technology, Beijing, China; ${ }^{3}$ Center of Research Experiment, Beijing University of Chinese Medicine, Beijing, China; ${ }^{4}$ West China School of Medicine, Sichuan University, Chengdu, China; ${ }^{5}$ Department of Medicine, China-Japan Friendship Hospital, Beijing, China

Contributions: (I) Conception and design: Q Li, Y Hou, B Zhao; (II) Administrative support: B Zhao, Y Li; (III) Provision of study materials or patients: X Zhang, R Mei, Y Li; (IV) Collection and assembly of data: B Zhao, Y Li, S Wang, P Wang; (V) Data analysis and interpretation: Q Li, Y Hou, B Zhao; (VI) Manuscript writing: All authors; (VII) Final approval of manuscript: All authors.

Correspondence to: Qiubing Li, MD. The Fourth Department of Healthcare, China-Japan Friendship Hospital, No.47 of Wenxueguan Road, Chaoyang District, Beijing 100029, China. Email: qiubingli24@163.com.

Background: Alzheimer's disease (AD) has gradually increased as society has aged and is now a serious social problem. In the clinical treatment of $\mathrm{AD}$, patients show improvement in cognitive function after treatment with the traditional Chinese medicine compound, Yizhi Sheng Hui (YZSH) decoction. This study systematically investigates the effect and pharmacology of the YZSH decoction on AD.

Methods: In this study, 24 SAMP8 AD model mice were randomly divided into three groups: an untreated control group, a group treated with the YZSH decoction, and a positive control group treated with donepezil hydrochloride. Eight SAMR1 mice were placed in the normal control group. A Morris water maze test and a step-down test were conducted at 8 and 13 weeks after continuous intragastric administration of the two drugs. After 13 weeks of administration, the hippocampal expression of A $\beta 1-42$ and tau protein were measured.

Results: There was no change in the latent period duration and the number of platform crossings in each group after 8 weeks of administration, but after 13 weeks of administration, the latent period of the treatment group and the positive control group were significantly shorter than the untreated control group. Initially, the SAMP8 mice showed a lower spatial exploration ability than the SAMR1 mice. However, after 13 weeks of administration, the treatment group and the control group exhibited a better exploration ability. Compared with the SAMR1 mice, the on-stage evasion time and step-down errors significantly increased in the untreated group. Compared with the untreated group, mice in the treatment group and the positive control group showed a shorter latent period after 8 weeks of administration, and the on-stage evasion time for both groups was significantly reduced after 13 weeks of administration. The treatment group showed fewer instances of electric shock. Hippocampal expression of A $\beta 1-42$ was high in the untreated group, was much lower in the positive control group, and no A $\beta 1-42$ expression was observed in the treatment group.

Conclusions: The YZSH decoction improved the learning and memory of mice with $\mathrm{AD}$, related to the inhibition of $\mathrm{A} \beta 1-42$ expression.

Keywords: Alzheimer's disease (AD); Yizhi Sheng Hui decoction (YZSH decoction); SAMP8 mice; $\beta$-amyloid protein; tau protein

Submitted Aug 18, 2020. Accepted for publication Mar 31, 2021.

doi: 10.21037/apm-20-1629

View this article at: http://dx.doi.org/10.21037/apm-20-1629 


\section{Introduction}

Alzheimer's disease (AD) is a progressive and irreversible brain deterioration disease. AD is characterized by brain atrophy and the subsequent decreased cognitive ability of patients. This eventually leads to the inability of patients with $\mathrm{AD}$ to perform activities of daily living, accompanied by psychiatric symptoms. More than half of all known dementia cases may be induced by $\mathrm{AD}$. A diagnosis of $\mathrm{AD}$ also causes enormous emotional and economic problems to the families of patients. In the past few decades, the incidence of $\mathrm{AD}$ has gradually increased as society has aged, and it effects up to $50 \%$ of people 85 years of age or older $(1,2)$. This makes $\mathrm{AD}$ a serious social problem. Therefore, the prevention and treatment of $\mathrm{AD}$ are of great social significance.

The pathogenesis of $\mathrm{AD}$ is still unclear, but the major pathological features of $\mathrm{AD}$ are known: the senile plaques of aggregated $\beta$-amyloid protein $(A \beta)$ and the accumulation of neurofibrillary tangles of hyperphosphorylated tau protein. Current studies on the pathogenesis of AD focus on the following aspects: (I) the synaptic dysfunction caused by the imbalance between the excitatory and inhibitory neurotransmitter system; (II) the A $\beta$ toxicity hypothesis; (III) the tau protein hypothesis; (IV) inflammation; and (V) vascular factors (3-8). A $\beta$ is one of the most studied molecules in the pathogenesis of $\mathrm{AD}$ and results suggest that changes in $A \beta$ metabolism (such as an increased $A \beta$ production and decreased $A \beta$ degradation) cause increased $\mathrm{A} \beta$ accumulation. Subsequently, oligomerization of $A \beta$ will impact the synaptic and/or neuronal function by inducing inflammation and formation of amyloid plaques. These brain tissue injuries are irreversible, so brain function will gradually deteriorate.

Currently, there are no effective therapies for AD. The medicines approved by the U.S. Food and Drug Administration for clinical therapy are acetylcholinesterase inhibitors and glutamate receptor antagonists. After long periods of clinical application, these drugs demonstrate some symptom improvement but do not effectively control the disease progression.

Therapies based on the $\mathrm{A} \beta$ toxicity hypothesis and the tau protein hypothesis, such as inhibiting the expression and aggregation of $A \beta$, facilitating the clearance of $\mathrm{A} \beta, \mathrm{A} \beta$-targeting triggered immunotherapy, inhibiting phosphorylation of tau protein, etc., have recently become the focus of anti-AD studies (9). In addition, treatment of $\mathrm{AD}$ with Chinese medicine has a multi-target mechanism and has demonstrated a positive outcome (10). A single Chinese herb (e.g., ginseng, tuckahoe, rehmannia, dogwood, Polygala tenuifolia Willd, and Acorus gramineus) may inhibit the expression and aggregation of $A \beta$, the phosphorylation of tau protein, regulate neurotransmitters, reduce inflammation, and eliminate free radicals. In clinical research, therapies based on compound traditional Chinese medicine may enhance the cognitive performance of patients with $\mathrm{AD}$ and improve the quality of their life through invigorating the spleen and kidney, removing phlegm, and promoting blood circulation (11-17).

In this group's clinical treatment of $\mathrm{AD}$, patients with $\mathrm{AD}$ showed some improvement in cognitive function after treatment with the traditional Chinese medicine compound, Yizhi Sheng Hui (YZSH) decoction. Its effects include coordinating the heart and the kidney. In order to further investigate the mechanism of YZSH, SAMP8 mice (AD model animals) are treated with the YZSH decoction, after which their learning and memory abilities are evaluated through a Morris water maze test and a stepdown test. The pharmacologic action is studied through $e x$ vivo immunohistochemical analysis. The following article is presented in accordance with the Animal Research: Reporting of In Vivo Experiments checklist (available at http://dx.doi.org/10.21037/apm-20-1629).

\section{Methods}

\section{Materials}

\section{Laboratory animals and grouping}

The animals used in this study included 24 male SAMP8 mice of the Alzheimer's Dementia model (weight: 18-22 g) and 8 male SAMR1 mice (weight: 18-22 g). The animals were provided by the experimental animal laboratory of the Peking University Medical Department. The mice were fed with a standard chow diet and housed at room temperature of $22 \pm 2{ }^{\circ} \mathrm{C}$. The SAMP8 mice were randomly divided into a model group, a decoction treatment group, and a positive control group treated with donepezil hydrochloride, by weight. There were eight mice in each group. The SAMR1 mice were used as the normal control group. All Animal experiments were performed under a project license (No. LA2019083) granted by the Peking University Institutional Animal Care and Use Committee. All applicable international, national, and/or institutional guidelines for the care and use of animals were followed. 


\section{Equipment}

The Morris water maze, the step-down platform, and the video analysis system were manufactured by Mobile Datum in Shanghai.

\section{Study methods}

\section{Administration of the Yizhi Sheng Hui decoction and donepezil hydrochloride}

All groups were fed via intragastric administration. The normal control group and the model group were continuously fed water for 13 weeks. The mice in the treatment group were fed a YZSH decoction made of red ginseng, tuckahoe, prepared rehmannia root, platycladi seed, Polygala tenuifolia willd, Semen sinapis, etc. (one dose decocted for $100 \mathrm{~mL}, 15 \mathrm{~mL} / \mathrm{kg} / \mathrm{d}$ ). The positive control group was fed a donepezil hydrochloride solution $(1 \mathrm{mg} / \mathrm{kg} / \mathrm{d})$ once per day continuously for 13 weeks, and the behavioral experiments were conducted 8 weeks and 13 weeks after administration.

\section{Morris water maze test}

The Morris water maze test is a classic behavioral neuroscience method that characterizes the abilities of small animals in spatial orientation and memory. The Morris water maze utilized in this study was composed of a cylindrical metal water pool $(60 \mathrm{~cm}$ in height and $120 \mathrm{~cm}$ in diameter), an automatic display, a surveillance device, a recording instrument, and a safety "island" (a $10 \mathrm{~cm}$ diameter platform). Clear water was poured into the pool until the water level was $1 \mathrm{~cm}$ above the platform. The water temperature was maintained at $23 \pm 2{ }^{\circ} \mathrm{C}$. At the edges of the pool, at equal distances, four marker points were placed to divide the pool into four quadrants. The platform was placed in the second quadrant.

\section{Navigation test}

Each animal was trained once per day for a period of 3 days. During training, the animal was placed into the pool, facing the wall. At the same time, a recording device was initiated so the latent period of the mouse searching for the platform was automatically recorded by the computer. If the mouse could not find the platform in one minute after entering the pool, the researcher guided it to the platform and set it on top for $30 \mathrm{~s}$, so it learned the pattern. On the fourth day, the mouse was placed in the pool (in the same location) to record its latent period of evasion. If the mouse could not find the platform in one minute, the latent period was recorded as $60 \mathrm{~s}$. After each training, the mouse was dried to prevent any stress response from low body temperature.

\section{Spatial exploration test}

On the fifth day, the platform in the second quadrant was removed. In the same location, the mouse was placed into the pool, facing the wall. The number of times the mouse crossed the pool in $60 \mathrm{~s}$ was recorded. The mouse's activities were captured by a fixed camera above the pool, and the recorded images were analyzed by EthoVision 3.0 software.

\section{Step-down test}

The mouse was placed in the apparatus for 2 min to adapt to the environment. The mouse was then subjected to an electric shock (by $0.7 \mathrm{~mA}$ ac current) so it would search for the platform to avoid the shock. The time it took for each mouse to jump onto the platform once subjected to the electric shock was recorded (evasion time) as the learning score. The mouse was tested again after $24 \mathrm{~h}$. For the test, the mouse was placed on the platform first, and for $3 \mathrm{~min}$ its errors were recorded to reflect its memory retention.

\section{Statistical analysis}

The data was analyzed through a chi-square $\left(\chi^{2}\right)$ test.

\section{Aß1-42 and tau protein expression in brain tissues}

The expression of $\mathrm{A} \beta 1-42$ and tau protein in the hippocampus of the mice was measured by immunohistochemistry. The brain tissue was harvested and fixed in 10\% formalin for three days. After it was embedded with paraffin, the fixed tissue was sliced into sections. The sections were then deparaffinized and hydrated. High-pressure antigen retrieval was performed using a citrate buffer $(\mathrm{pH}=6.0)$. The sections were treated with $3 \%$ hydrogen peroxide in methanol for $15 \mathrm{~min}$ to quench the endogenous peroxidase, followed by an incubation with normal serum to block any non-specific staining. Rabbit anti-A $\beta 1-42$ or rabbit anti-tau was used to incubate the sections overnight at $4{ }^{\circ} \mathrm{C}$. After washing, the tissue sections were treated with the biotinylated anti-rabbit secondary antibody, followed by additional incubation with the streptavidin-horseradish peroxidase complex. After staining with the diaminobenzidine kit, the sections were counterstained with hematoxylin. A negative control was treated simultaneously with the same procedure, but phosphate-buffered saline was used instead of the primary antibody.

Tumor tissue expression levels of $\mathrm{A} \beta 1-42$ and tau 


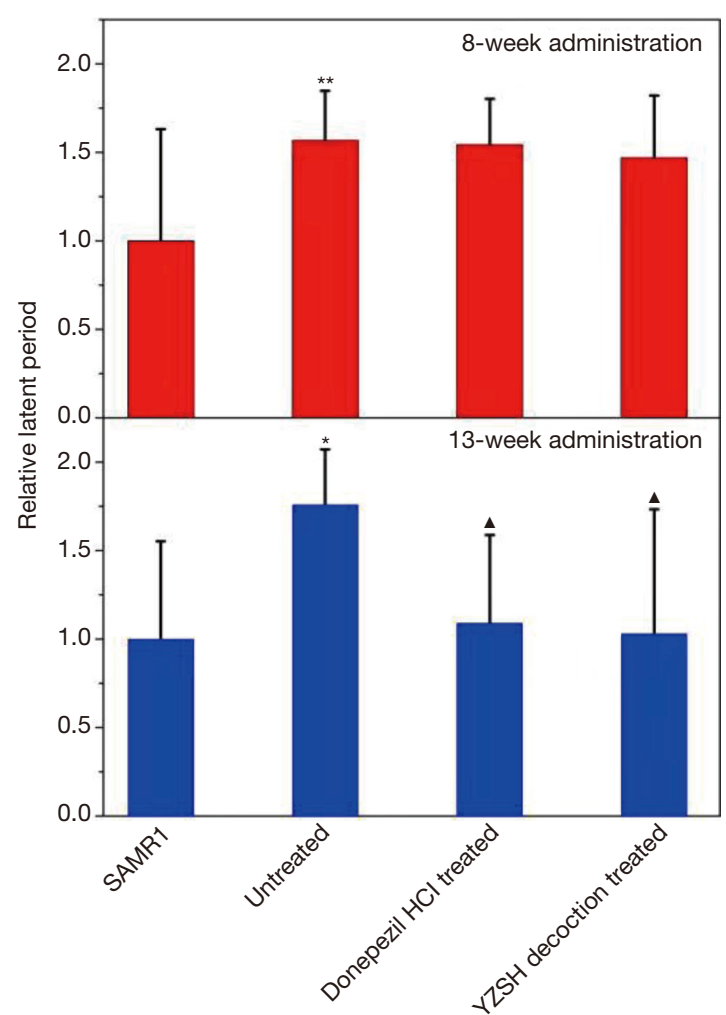

Figure 1 Latent periods after 8-week and 13-week administration during the navigation experiment of the SAMR1 group, the untreated group, the donepezil hydrochloride treated group, and the YZSH decoction treated group $(\bar{x} \pm \mathrm{s}, \mathrm{n}=8)$. Red column: after 8 -week treatment. Blue column: after 13 -week treatment. ${ }^{*} \mathrm{P}<0.05$, ${ }^{* *} \mathrm{P}<0.01$ vs. SAMR1; ${ }^{\star} \mathrm{P}<0.05$ vs. untreated group.

Table 1 Effects of the YZSH decoction on the spatial searching capacity of the SAMP8 mice $(\bar{x} \pm \mathrm{S}, \mathrm{n}=8)$

\begin{tabular}{lcc}
\hline \multirow{2}{*}{ Group } & \multicolumn{2}{c}{ The number of platform crossing } \\
\cline { 2 - 3 } & 8-week & 13 -week \\
\hline SAMR1 & $1.15 \pm 1.28$ & $1.13 \pm 1.25$ \\
Untreated & $0.00 \pm 0.00^{\star *}$ & $0.13 \pm 0.35^{\star *}$ \\
Donepezil hydrochloride & $0.08 \pm 0.29$ & $1.33 \pm 1.30^{\star}$ \\
YZSH decoction & $0.21 \pm 0.58$ & $1.46 \pm 1.76^{\star}$ \\
\hline
\end{tabular}

${ }^{\star \star} \mathrm{P}<0.01$ vs. SAMR1 group; ${ }^{\wedge} \mathrm{P}<0.05$ vs. model group. protein were further determined quantificationally through enzyme-linked immunosorbent assay (ELISA).

\section{Results}

Effects of the Yizhi Sheng Hui decoction on spatial differentiation ability, learning ability, and memory of the SAMP8 mice

After 8 weeks of administration, the Morris water maze test results showed that the latent period for each group decreased during the four-day training (Table S1). There was almost no difference in the latent period for the SAMP8 mice treated with different agents, all of which were much longer than that of the SAMR1 control group (shown in the upper layer in Figure 1). The number of platform crossings for the untreated and donepezil hydrochloride treated SAMP8 mice were close to 0 , while it was 0.21 for the group treated with the YZSH decoction (Table 1). These results suggest that the YZSH decoction improves the spatial searching capacity of mice with $\mathrm{AD}$. These results show no noteworthy improvement in the learning ability and memory of the mice. In particular, the treatment with different drugs did not have noticeable effects after 8 weeks of treatment $(\mathrm{P}>0.05)$.

The Morris water maze test was performed again after 13 weeks of drug administration. As is illustrated in Table S2, as the number of training times increased, the latent period time decreased in the navigation test for the SAMP8 mice treated with donepezil hydrochloride and the YZSH decoction. The training times finally reached the level of the SAMR1 control group whereas the latent period only varied slightly for the untreated group (the bottom layer in Figure 1). The latent period for the mice treated with the YZSH decoction was 33.56 s. This was close to that of the SAMR1 control mice after two days of training (31.50 s). The mice treated with donepezil hydrochloride showed longer latent periods (46.03 s). These results suggest that the YZSH decoction exhibited a stronger effect than donepezil hydrochloride.

In the subsequent spatial exploration test, the spatial 
Table 2 Number of errors in the step-down test after 8-week and 13 -week administration $\left(\bar{x}_{ \pm} \mathrm{s}, \mathrm{n}=8\right)$

\begin{tabular}{lcc}
\hline \multirow{2}{*}{ Group } & \multicolumn{2}{c}{ Number of errors } \\
\cline { 2 - 3 } & 8 -week & 13 -week \\
\hline SAMR1 & $1.46 \pm 0.97$ & $0.83 \pm 0.58$ \\
Untreated & $2.69 \pm 1.49^{\star}$ & $1.44 \pm 0.53^{*}$ \\
Donepezil HCl & $1.58 \pm 1.16$ & $0.83 \pm 0.72^{\star}$ \\
YZSH decoction & $1.79 \pm 1.31$ & $0.64 \pm 0.74^{\star}$ \\
\hline
\end{tabular}

${ }^{*} \mathrm{P}<0.05$ vs. SAMR 1 group; ${ }^{\wedge} \mathrm{P}<0.05$ vs. model group.

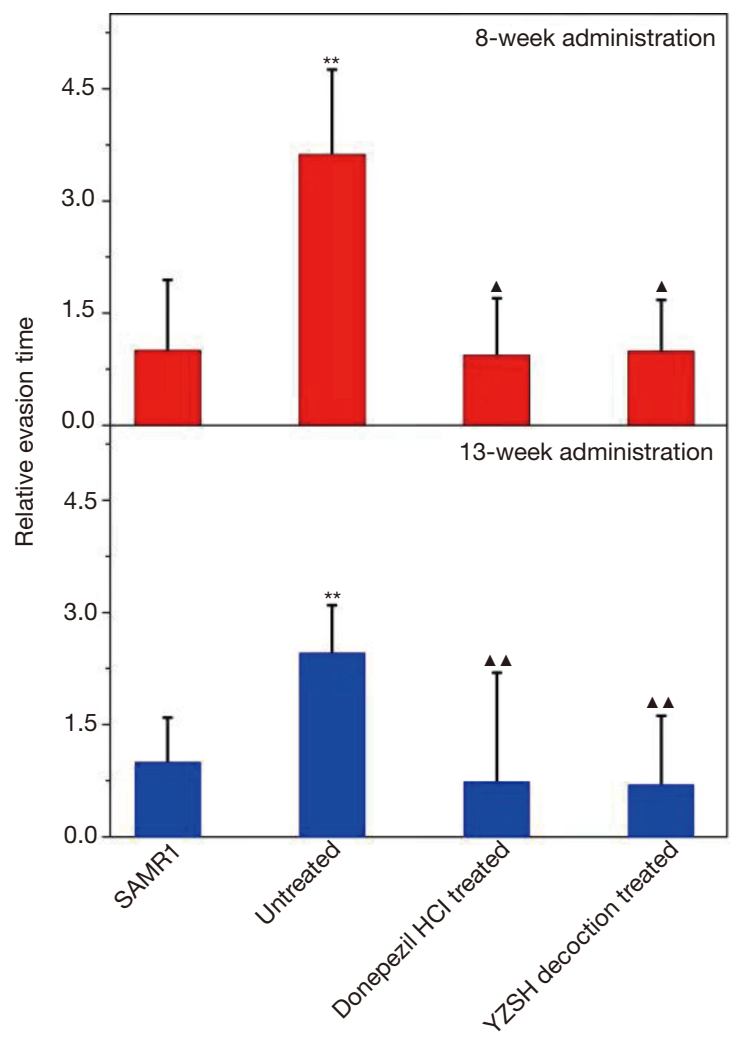

Figure 2 Evasion time after 8-week and 13-week administration during the step-down test of the SAMR1 group, the untreated group, the donepezil hydrochloride treated group, and the YZSH decoction treated group $(\bar{x} \pm \mathrm{S}, \mathrm{n}=8)$. Red column: after 8 -week treatment. Blue column: after 13 -week treatment. ${ }^{* *} \mathrm{P}<0.01$ vs. SAMR1; ${ }^{\mathbf{}} \mathrm{P}<0.05,{ }^{\Delta \wedge} \mathrm{P}<0.01$ vs. untreated group. searching ability of the treated mice also improved after the 13-week administration. As is illustrated in Table 1, the number of platform crossings were 1.33 and 1.46 for the mice treated with donepezil hydrochloride and $\mathrm{YZSH}$ decoction, respectively $(\mathrm{P}>0.05)$. This reached the level of the control group (the SAMR1 mice), whereas the untreated mice showed no advances. These results suggest that the medicine variably improves the spatial searching ability of the model mice with $\mathrm{AD}$.

\section{Effects of the Yizhi Sheng Hui decoction on the passive conditioned evasion reflex of the SAMP8 mice}

The step-down test (based on the active habits of mice) was performed to determine the passive evasion conditioned reflex. The therapeutic effect was observed in the stepdown test after 8 weeks of administration, unlike the Morris water maze test (Table 2). The evasion time on-stage (Figure 2) and the step-down error times for both treated groups were reduced to the level of healthy SAMR1 mice, while the untreated mice showed a longer on-stage evasion time and had increased instances of step-down errors. These results indicate that the YZSH decoction effectively remits cognitive decline.

\section{Aß1-42 and tau protein expression in the brain tissues of SAMP8 mice}

To understand the pharmacology of the YZSH decoction, histological studies of the brain were conducted. The results in the upper panel in Figure $3 A$ clearly demonstrate that there was a high expression of $A \beta 1-42$ in the hippocampi of the untreated SAMP8 mice while there was no expression in the hippocampi of the SAMP8 mice treated with the YZSH decoction and donepezil hydrochloride. The staining assays (shown in the lower panel in Figure $3 A$ ) exhibited no tau protein expression in all groups.

The expression levels of $\mathrm{A} \beta 1-42$ and tau protein in the brains of the mice were determined quantitatively via the ELISA method. As is shown in Figure $3 B$ and $3 C$, the expression of $A \beta 1-42$ in the SAMP8 mice treated with the 
A

A

SAMR1

Untreated
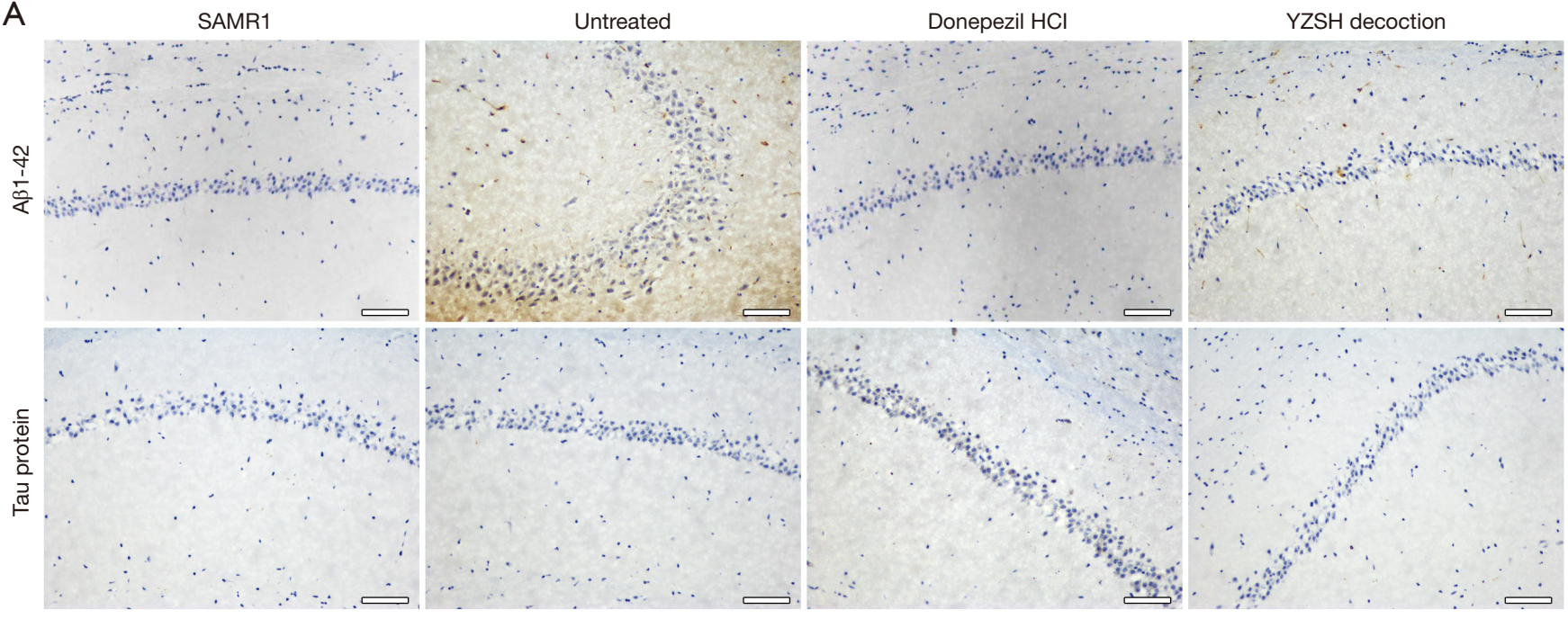

B

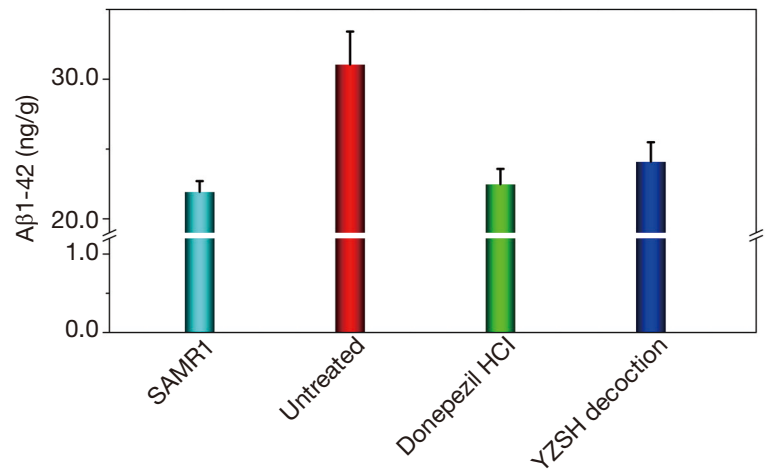

$\mathrm{C}$

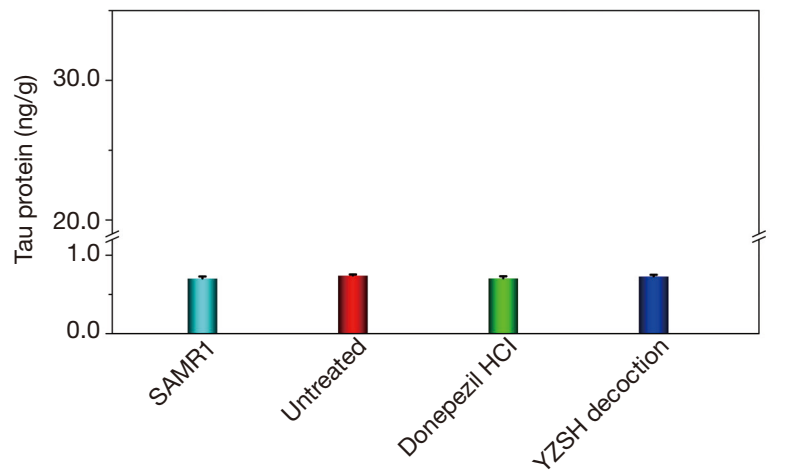

Figure 3 The effect of the YZSH decoction on A $11-42$ and tau protein expression in the brain tissues of the SAMP8 mice. Immunohistochemical staining images of A $\beta 1-42$ and tau protein in the hippocampus, and the scale bar corresponds to $100 \mu \mathrm{m}(\mathrm{A})$; quantified expression level of A $11-42$ (B) and tau protein (C) obtained through ELISA.

YZSH decoction and donepezil hydrochloride was downregulated by approximately $25 \%$ (very close to the SAMR 1 control group) while the expressions of tau protein varied only slightly for all the groups. These results suggest that the YZSH decoction relieves AD symptoms by adjusting the expression of $\mathrm{A} \beta 1-42$.

\section{Discussion}

In traditional Chinese medicine theory, the cognitive hypofunction and psychological behavioral symptoms of patients with $\mathrm{AD}$ are attributed to the abnormity of the mind that is related to the breakdown of the normal physiological coordination between the heart and the kidney. Traditional Chinese medical literature states that dementia can be treated by restoring the normal coordination between the heart and the kidney. In this study, the YZSH decoction (proven to possess an effect on repairing and coordinating heart and kidney functions) exhibited an obvious therapeutic effect on improving the cognitive function and the behavioral symptoms of patients with $\mathrm{AD}$. In addition, the mechanism was explored to promote the use of the $\mathrm{YZSH}$ decoction in the clinical treatment of $\mathrm{AD}$.

Senescence accelerated mice (SAM) display the typical characteristics of a short lifespan, an accelerated aging process, and pathological aging changes. In addition to these general aging symptoms, SAMP8 mice possess an age-related decline in learning ability and memory. Protein grains have been found in the brains of SAMP8 mice that are similar to senile plaques $(18,19)$. In this study, the YZSH decoction significantly reduced the latent period of evasion for SAMP8 mice in the water maze and improved their spatial searching capacity (i.e., reduced the step-down 
evasion period and error times). These results indicate that the YZSH decoction improves the learning ability and memory of SAMP8 mice.

Combined with the pathologic results of the low expression of AB1-42 in the hippocampus of the SAMP8 mice treated with the YZSH decoction compared to the untreated and control groups, the decoction likely improved the learning and memory of the SAMP8 mice by inhibiting $A \beta$ protein expression and reducing neuron injury. Although $\mathrm{AD}$ pathogenesis remains unclear, senile plaques and neurofibrillary tangles have been confirmed as its classical pathological features. Previously published works have indicated that senile plaques form from the abnormal aggregation of $\mathrm{A} \beta$ proteins $(20,21)$ and neurofibrillary tangles are mainly composed of hyperphosphorylated tau proteins $(21,22)$. Current clinical medicines, based on the neuron protection hypothesis, exhibit unsatisfying therapeutic effects. Therefore, understanding the role of $\mathrm{A} \beta$ proteins and tau proteins in $\mathrm{AD}$ pathogenesis and therapy has become the focus of $\mathrm{AD}$ research. In the most recent $\mathrm{AD}$ diagnostic standards, including those of the International Working Group and the National Institute of Aging and Alzheimer's Association, $\mathrm{A} \beta$ and tau proteins are treated as biomarkers in the diagnosis of $\operatorname{AD}(23,24)$. Currently, medical research based on the $\mathrm{A} \beta$ hypothesis and the tau hypothesis on reducing $\mathrm{A} \beta$ synthesis, inhibiting $\mathrm{A} \beta$ aggregation, promoting $\mathrm{A} \beta$ clearance, and inhibiting the hyperphosphorylation and aggregation of tau proteins have become important fields for the prevention and therapy of AD. Traditional Chinese medicine may provide new approaches to the multi-target and multi-mechanism perspectives for $\mathrm{AD}$ prevention and treatment $(11,25,26)$.

The decoction's inhibitory mechanism on the expression of $A \beta 1-42$ (either by inhibiting $A \beta$ synthesis/aggregation or by promoting its clearance) must be studied in the future. In this study, the expression of tau protein in the SAMP8 mice in all groups was nearly unchanged, and they were all close to that of the SAMR1 control group. This phenomenon was inconsistent with reference reports (27) so it should be investigated further to more clearly understand the mechanism(s) of $\mathrm{AD}$.

\section{Conclusions}

The YZSH decoction improved the learning and memory of the SAMP8 mice, and it noticeably reduced the expression of A $\beta 1-42$. Therefore, the YZSH decoction improved the learning and memory of the mice with $\mathrm{AD}$ by inhibiting the formation of $\mathrm{A} \beta 1-42$ in the hippocampus.

\section{Acknowledgments}

Funding: The authors thank the National Natural Science Foundation of China (NSFC) (No. 81471726, No. 81671754) for financial support.

\section{Footnote}

Reporting Checklist: The authors have completed the ARRIVE reporting checklist. Available at http://dx.doi. org/10.21037/apm-20-1629

Data Sharing Statement: Available at http://dx.doi. org/10.21037/apm-20-1629

Conflicts of Interest: All authors have completed the ICMJE uniform disclosure form (available at http://dx.doi. org/10.21037/apm-20-1629). The authors have no conflicts of interest to declare.

Ethical Statement: The authors are accountable for all aspects of the work in ensuring that questions related to the accuracy or integrity of any part of the work are appropriately investigated and resolved. All Animal experiments were performed under a project license (No. LA2019083) granted by the Peking University Institutional Animal Care and Use Committee. All applicable international, national, and/or institutional guidelines for the care and use of animals were followed.

Open Access Statement: This is an Open Access article distributed in accordance with the Creative Commons Attribution-NonCommercial-NoDerivs 4.0 International License (CC BY-NC-ND 4.0), which permits the noncommercial replication and distribution of the article with the strict proviso that no changes or edits are made and the original work is properly cited (including links to both the formal publication through the relevant DOI and the license). See: https://creativecommons.org/licenses/by-nc-nd/4.0/.

\section{References}

1. Querfurth HW, LaFerla FM. Alzheimer's disease. N Engl J Med 2010;362:329-44.

2. Yan GL. Logistic Regression Risk Factor Analysis of Alzheimer's Disease. Chin J Geriatr 2012;32:1903. 
3. Kano O, Ito H, Takazawa T, et al. Clinically meaningful treatment responses after switching to galantamine and with addition of memantine in patients with Alzheimer's disease receiving donepezil. Neuropsychiatr Dis Treat 2013;9:259-65.

4. Wilkinson D, Anddersen HF. Analysis of the effect of memantine in reducing the worsening of clinical symptoms in patients with moderate to severe Alzheimer's disease. Dement. Geriatr Cogn Disord 2007;24:138-45.

5. Huang FD. Gradual understanding the role of -amyloid protein in Alzheimer's Disease. Life Sci 2014;6:9-14.

6. Wan Z. The effect of hyperphosphorylated tau protein on Alzheimer's disease pathogenesis. J Med Postgrad 2010;23:439-542.

7. Swardfager W, Lanctôt K, Rothenburg L, et al. A meta analysis of cytokines in Alzheimer's disease. Biol Psychiatry 2010;68:930-41.

8. Wang L, Zhu MF. Research progress on pathogenesis of Alzheimer's disease. Jilin Med J 2013;34:531-2.

9. Bi DL, Wen L, Xiong W, et al. Clinical research progress and possible molecular targets of drugs for Alzheimer's disease. Chin J Pharm Toxicol 2015;29:507-36.

10. Jia JP, Liu JH. Advances in the study on pathologic mechanism and treatment of Alzheimer's disease. Chinese Journal of Contemporary Neurology and Neurosurgery 2010;10:43-8.

11. Zhang G, Wu JJ, Jiang M. Research progress on traditional Chinese medicine for treating Alzheimer's disease. Chinese Journal of Experimental Traditional Medical Formulae 2014;20:217-22.

12. Li N. Research progress of Ginsenoside $\mathrm{Rg} 1$ in the treatment of neuro degenerative diseases. Chinese Journal of Gerontology 2012;32:3345-7.

13. Gao BB, Xu SP, Liu XM, et al. Comparison of Nootropic effects of Kaixinsan Prescription and Kaixinsan without Poria cocos. Chinese Journal of Comparative Medicine 2010;20:57-62.

14. Sun WX, An HM. Effects of prepared radix rehmanniae and related herbal formula in treatment of denile dementia. Chinese Archives of Traditional Chinese Medicine 2014;32:766-8.

15. Yao HT, Ma JL, Zhang XB, et al. Effect of Polysaccharide from Fructus Corni on tau proteins in rats with Alzheimer's disease. Chinese Journal of Gerontology 2013;33:2838-41.

16. Zhang ZH, Wang XL, Liu SL, et al. Review of experimental studies on Acorus tatarinowii and Polygala tenuifolia in the treatment of Alzheimer's disease. Hubei
Journal of Traditional Chinese Medicine 2012;34:32-4.

17. Mu JX, Guo F, Cui LX, et al. Effect of polygala on tau protein phosphorylation of hippocampal neurons of Alzheimer disease rat models. Journal of Shanxi College of Traditional Chinese Medicine 2013;14:22-4.

18. Miyamoto M. Characteristics of age related behavioral changes in senescence accelerated mouse SAM P8 and SAM P10. Exp Gerontol 1997;32:139.

19. Kuo H, Ingram DK, Walker LC, et al. Simlilarities in the aged-related hippocampal deposition of periodic acidschiff-positive granules in the senescence-accelerated mouse P8 and C57BL/6 mouse strains. Neuroscience 1996;74:733-40.

20. Glenner GG, Wong CW. Alzheimer's disease and Down's syndrome: sharing of a unique cerebrovascular amyloid fibril protein. Biochem Biophys Res Commun 1984;122:1131-5.

21. Lee VM, Goedert M, Trojanowski JQ. Neurodegenerative tauopathies. Annu Rev Neurosci 2001;24:1121-59.

22. Gong CX, Liu F, Grundke-Iqbal I, et al. Post translational modifications of tau protein in Alzheimer's disease. J Neural Transm 2005;112:813-38.

23. Sperling RA, Aisen PS, Beckett LA, et al. Toward defining the preclinical stages of Alzheimer's disease: recommendations from the National Institute on AgingAlzheimer's Association work groups on diagnostic guidelines for Alzheimer's disease. Alzheimers Dement 2011;7:280-92.

24. Dubois B, Feldman HH, Jacova C, et al. Advancing research diagnostic criteria for Alzheimer's disease: the IWG-2 criteria. Lancet Neurol 2014;13:614-29.

25. Wang JT, Deng JL, Zhang P, et al. Research progress about the onset related factors treatment for Alzheimer's disease. Chinese Journal of Neuroanatomy 2013;29:705-10.

26. Liu YL, Hu WM Treatment progress of Alzheimer's disease. Chinese Remedies \& Clinics 2014;14:56-60.

27. Canudas AM, Gutierrez-Cuesta J, Rodríguez MI, et al. Hyperphosphorylation of microtubule-associated protein tau in senescence-accelerated mouse (SAP). Mech Ageing Dev 2005;126:1300-4.

Cite this article as: Li Q, Hou Y, Zhao B, Li Y, Zhang X, Mei R, Wang S, Wang P, Liu Y. The effect and pharmacology of Yizhi Sheng Hui decoction on Alzheimer's disease. Ann Palliat Med 2021;10(5):5244-5251. doi: 10.21037/apm-20-1629 
Supplementary

Table S1 Latent period in 8 weeks after administration during the navigation experiment $\left(\bar{x}_{ \pm} \mathrm{s}, \mathrm{n}=8\right)$

\begin{tabular}{lcccc}
\hline Group & $1 \mathrm{~d}$ & $2 \mathrm{~d}$ & $3 \mathrm{~d}$ & $4 \mathrm{~d}$ \\
\hline SAMP1 & $40.84 \pm 18.71$ & $42.69 \pm 21.04$ & $38.76 \pm 24.10$ & $34.00 \pm 21.49$ \\
Untreated & $60.00 \pm 0.00^{\star \star}$ & $57.15 \pm 10.57^{\star}$ & $56.69 \pm 11.34^{\star}$ & $53.23 \pm 15.00^{\star \star}$ \\
Donepezil HCl & $59.15 \pm 3.05$ & $50.31 \pm 19.09$ & $60.00 \pm 0.00$ & $52.42 \pm 13.72$ \\
YZSH decoction & $54.57 \pm 11.25$ & $56.64 \pm 12.56$ & $46.71 \pm 19.52$ & $49.93 \pm 17.63$ \\
\hline
\end{tabular}

${ }^{\star} \mathrm{P}<0.05,{ }^{\star \star} \mathrm{P}<0.01$ vs. SAMP1.

Table S2 Latent period in 13 weeks after administration during the navigation experiment $(\bar{x} \pm \mathrm{s}, \mathrm{n}=8)$

\begin{tabular}{lcccc}
\hline Group & $1 \mathrm{~d}$ & $2 \mathrm{~d}$ & $3 \mathrm{~d}$ & $4 \mathrm{~d}$ \\
\hline SAMP1 & $28.64 \pm 20.38$ & $36.89 \pm 21.08$ & $31.50 \pm 18.79$ & $27.13 \pm 14.97$ \\
Untreated & $52.33 \pm 17.95^{\star \star}$ & $55.53 \pm 9.38^{\star}$ & $52.70 \pm 4.33^{\star \star}$ & $47.75 \pm 14.83^{\star}$ \\
Donepezil HCl & $53.40 \pm 13.62$ & $53.97 \pm 11.17$ & $46.03 \pm 16.90^{\mathbf{\Delta}}$ & $29.56 \pm 14.77^{\mathbf{\Delta}}$ \\
YZSH decoction & $48.38 \pm 19.63$ & $43.61 \pm 20.17$ & $33.56 \pm 22.40^{\boldsymbol{\Lambda}}$ & $28.00 \pm 19.65^{\mathbf{\Delta}}$ \\
\hline
\end{tabular}

${ }^{*} \mathrm{P}<0.05,{ }^{* *} \mathrm{P}<0.01$ vs. SAMP1; ${ }^{\mathbf{A}} \mathrm{P}<0.05,{ }^{\Delta \boldsymbol{}} \mathrm{P}<0.01$ vs. model group. 